\title{
PIXO E CENAS DISSENSUAIS EM BELO HORIZONTE: ANTAGONISMOS ENTRE A FORÇA DA LEI E A EMERGENCIA DOS PIXADORES COMO SUJEITOS POLÍTICOS ${ }^{1}$
}

\author{
Ângela Cristina Salgueiro Marques ${ }^{2}$ \\ Ana Karina de Carvalho Oliveira ${ }^{3}$
}

\section{Resumo}

Este artigo se propõe a observar como o poder público de Belo Horizonte tem intensificado o combate à pixação na cidade, ao mesmo tempo em que pixadores têm aparecido publicamente com novas formas de narrar o pixo e suas experiências. Nessas duas esferas, há duas construções completamente diferentes sobre o que significa "ser pixador", configurando uma cena de interação e interlocução tensa e dissensual. Mais do que isolá-las e opô-las, o interesse se dá em perceber como os pixadores podem utilizar os recursos dessa cena para aparecerem como sujeitos políticos.

Palavras-chave: pixadores; poder público; cenas de dissenso; sujeitos políticos.

\section{INTRODUÇÃO}

Entre as diversas formas de expressões gráficas encontradas no espaço urbano, a pixação (ou pixo ${ }^{4}$ ) pode ser vista como aquela que está à margem da margem, sendo, possivelmente, a mais condenada. Um dos motivos parece ser a ilegibilidade dos traços para a maioria das pessoas que não compartilham daquele código de escrita. Outro, conforme aponta Lassala (2010), associa-se ao fato de que pixadores não têm um histórico de envolvimento em ações comerciais ou educativas, públicas ou privadas. Se, por um lado, tais ações podem aumentar a visibilidade de intervenções gráficas urbanas, por outro, podem significar sua conformação a determinados padrões e expectativas, como ocorre com o grafite. Dessa forma, pixadores continuam a ser vistos como vândalos e criminosos, enquanto adeptos de outras formas de intervenção, também nascidas nas ruas, ganham status de artistas.

\footnotetext{
${ }^{1}$ Este trabalho foi realizado com o apoio da CAPES e do CNPq.

${ }^{2}$ Doutora em Comunicação Social pela UFMG. Professora do Programa de Pós-graduação da UFMG. Pesquisadora do CNPq. Email: angelasalgueiro@gmail.com

3 Doutoranda em Comunicação Social pela Universidade Federal de Minas Gerais (UFMG). Bolsista Capes. E-mail: anakarina.akco@gmail.com

${ }^{4}$ Neste texto, é feita a opção pelo emprego da grafia da palavra "pixação" e suas derivações com "x", como é adotada por seus praticantes.
} 
Na cidade de Belo Horizonte, foco da investigação deste texto, um complexo esquema de combate ao pixo vem sendo constituído, desde 2010, por meio da articulação entre prefeitura, polícias Militar e Civil, e Ministério Público, e da criação sequencial de legislações, projetos e medidas que têm como objetivo erradicar o pixo na capital. Ao mesmo tempo, é possível apontar a presença de ações pontuais, mas importantes, de "aparecimento" e articulação entre os próprios pixadores, que têm encontrado formas para narrar suas experiências a fim de mostrar que o pixo significa, para eles, muito mais do que o poder público apresenta em suas informações e dados oficiais. Além disso, eles parecem querer mostrar que eles próprios, enquanto sujeitos, são muito mais do que os enquadramentos criminais que the são destinados. Para tanto, se articulam com outros sujeitos interessados em problematizar e discutir os dissensos entre as formas de uso e ocupação da cidade estabelecidas pelo poder público e os modos de apropriação e produção que os sujeitos realizam nela cotidianamente. Há aí, então, duas formas diversas e conflitantes de construção de sentido sobre "ser pixador": uma, pelo crime que assujeita; outra, pela experiência, que destaca a potência da vida e dos processos de subjetivação.

Acreditamos que as tensões entre as políticas antipixação do poder público de Belo Horizonte e as discussões e ações marginais sobre a pixação na cidade podem criar espaços institucionais de enunciação e interação, promovendo cenas de conflito em que processos legais e de justificação pública podem ser questionados, abrindo espaço para a reconfiguração de determinados sentidos sobre igualdade e justiça. Assim, nos interessa investigar a potência comunicativa que essas tensões guardam para a criação de cenas de dissenso (RANCIÈRE, 1996), em que se disputam diferentes visões e relações sobre a cidade, sobre formas de apropriação, uso e experiência, e sobre o que é ser pixador. Buscamos entender a dinâmica de aparecimento dos pixadores de Belo Horizonte, com atenção às suas ações e aos seus modos de organização, interação e articulação com outros atores, instituições e poderes, observando os entendimentos e dissensos que aí se constroem.

A primeira parte do artigo traz um breve histórico da pixação. A segunda parte apresenta algumas das ações e articulações marginais que têm discutido o pixo em Belo Horizonte, paralelamente às ações empreendidas pelo poder público municipal no combate à pixação. Na terceira parte do texto, trazemos uma reflexão acerca da cena de dissenso que configura o contexto observado, identificando os atores envolvidos; suas formas de inscrição e visibilidade; os argumentos por eles evocados; as formas de relação, interação ou exclusão que ali se estabelecem; e aquilo que aponta para uma reconfiguração do modo de compreender e partilhar o comum.

\footnotetext{
5 Tomamos aqui a noção de "aparecimento" tal como definida por Hannah Arendt (2000), ou seja, não só como ganhar visibilidade, mas também como surgir em uma cena de enunciação e presença construída pelo próprio sujeito e seus interlocutores: "as coisas vivas aparecem em cena como atores em um palco montado para elas. Aparecer significa sempre parecer para outros, e esse parecer varia de acordo com o ponto de vista e com a perspectiva dos espectadores" (2000, p.18 e 19). A perspectiva de Arendt soma-se à descrição que Rancière faz da cena de dissenso, conceito central à nossa investigação.
} 


\section{DO GRAFFITI NOVA-IORQUINO A PIXAÇÃO BRASILEIRA}

Na literatura sobre intervenções gráficas urbanas, vários autores (BAUDRILLARD, 1979; FRANCO, 2009; GITAHY, 2012; KNAUSS, 2001) apontam para o maio de 1968, em Paris, como o marco do surgimento dessa forma de interação com e apropriação dos espaços da cidade. Naquele momento, os jovens estudantes registravam nos muros as reivindicações e protestos que expressavam em suas manifestações. Contudo, ainda que essas inscrições tenham grande importância na história dessas formas de intervenção, é na Nova York do início dos anos 1970 que surgem as primeiras inscrições designadas especificamente como grafites.

Para Knauss (2001), a comercialização de tintas em spray portátil foi fundamental para o desenvolvimento do grafite. Ele conta que os primeiros relatos da imprensa nova-iorquina sobre o fenômeno datam de 1971 e apresentam a recorrência da inscrição "TAKI 138" pintada em spray pela cidade ("TAKI" era o codinome de um rapaz de 17 anos, e "138" era o número da sua casa). A partir daí várias outras marcas semelhantes começaram a surgir, seguindo uma configuração comum: formatos simples e nenhuma mensagem, apenas codinomes, acompanhados, muitas vezes, pelos nomes das ruas e/ou números das quadras onde os seus autores residiam. Alguns anos depois, começaram a surgir siglas de grupos, como TKA (The Kool Artists) e 3YB (Three Yard Boys).

No Brasil, as inscrições nos muros também começaram como ecos dos gritos repreendidos nas ruas, durante a ditadura militar. Contudo, nas décadas de 1970 e 1980, outras inscrições em spray, com um teor bastante diferente, é que começaram a aguçar a curiosidade das pessoas, como Celacanto Provoca Maremoto (que suscitou respostas, como "Perdigoto ataca Celacanto" " "Wackapaow mata Perdigoto e salva Celacanto") e Lerfá Mú (GITAHY, 2012), que ficaram tão conhecidas e estiveram tão presentes na imprensa que chegaram a ser apropriadas pela publicidade 6 . Contudo, com a disseminação da prática e a variedade de marcas pelas cidades, que começavam a assumir o formato das assinaturas de indivíduos e grupos, não demorou para que, já ao final dos anos 1970, a curiosidade fosse substituída pelos esforços para limpar e coibir as inscrições, que começavam a ser identificadas como "pichações" e relacionadas a atos de depredação, vandalismo e poluição do patrimônio público.

De acordo com Gitahy (2012), o termo "pichação" tem origem na Idade Média, quando padres escreviam com piche $e^{7}$ nas paredes de conventos “rivais”. De lá para cá, as inscrições nos muros passaram por várias modificações e, na forma que assumiram atualmente, no Brasil, tornaram-se "pixação", com "x", contrariando a ortografia formal e se relacionando diretamente com a experiência da prática na rua.

\footnotetext{
6 Algumas imagens de anúncios publicitários utilizando as frases de tais inscrições podem ser vistas em: <http://bardobulga.blogspot.com.br/2011/09/quando-celacanto-provocava-maremoto.html>. Acesso em 11/10/2015. ${ }^{7}$ Material derivado do petróleo, também conhecido como "breu" ou "betume".
} 
De acordo com Pereira (2005), são três as fases da pixação, identificadas, segundo ele, pelos próprios pixadores: 1) nos muros, feitas do chão; 2) nos topos dos prédios e outros lugares altos; e 3) na extensão das fachadas dos prédios, acessadas a partir de sua escalada, sendo que, quanto mais alto o ponto alcançado, mais "ibope ${ }^{8 "}$ aquele pixador obtém para si e para seu grupo. Gitahy (2012) e Lassala (2010) apresentam, ainda, o "grapixo" como uma técnica intermediária entre pixação e grafite? ${ }^{9}$ Aliás, cabe ressaltar que essas duas formas de escrita urbana são tão próximas quanto conflituosas, especialmente quando a segunda é vista como um antídoto para a primeira.

Segundo Pereira (2005), o grafite também passou por um período de condenação em seu início, e esse quadro só começou a mudar com a disseminação da pixação, quando o julgamento estético colocou ambas em comparação e fez sua escolha: decidiu-se que o primeiro era uma intervenção boa, ao contrário da segunda. Para o autor, "enquanto a pixação se enquadra na transgressão, no feio e no vandalismo, o grafite situa-se do lado da ordem, do belo e da política pública" (PEREIRA, 2005, p.28). É preciso considerar, contudo, que enquanto o grafite chega ao Brasil pelas mãos de artistas plásticos com formação superior (jovens brancos, instruídos, de classe média), a pixação se dissemina como um meio de expressão próprio das periferias (de jovens negros, pobres, com baixa escolaridade), e essa diferença sobre quem produz cada intervenção tem forte implicação na diferença da visibilidade de uns como artistas e outros como marginais.

A partir do que é apresentado por Pereira (2005), é possível perceber que um dos pontos mais atacados na pixação é o fato de ela não transmitir uma mensagem acessível a todos, o que faz com que ela seja associada a um ato vândalo movido apenas pela vaidade de marcar o próprio nome pela cidade. Contudo, se a ilegibilidade é um dos principais motivos pelos quais grande parte da população estranha e desaprova a pixação, ela pode ser vista como característica de um saber construído por essa prática, e mostra o investimento do pixador em desenvolver seu traço. Goma, pixador de Belo Horizonte, afirma que o pixo não precisa de uma frase legível porque a marca em si é uma mensagem de descontentamento, que não precisa ser lida para que tenha tal significado ${ }^{10}$.

\footnotetext{
8 "Ibope" é o termo utilizado pelos pixadores para se referir à fama e ao reconhecimento gerados entre os próprios grupos a partir da quantidade de pixações de um mesmo grupo ou pixador encontradas pela cidade e pelo grau de dificuldade enfrentado para pixar cada lugar. (LASSALA, 2010; PEREIRA, 2005)

${ }^{9} \mathrm{O}$ grapixo apresenta a assinatura comum ao pixo, porém pintada em formato diferente e em mais cores, assemelhando-se a uma ilustração.

10 Depoimento do pixador durante debate no evento "Pixo é Direito: diálogo aberto entre pixação e direito", realizado em 16 de maio de 2014, na Faculdade de Direito da Universidade Federal de Minas Gerais, pelo projeto Cidade e Alteridade.
} 


\section{SER PIXADOR EM BH: DUAS PERSPECTIVAS EM CONFLITO}

Desde 1991, Belo Horizonte possui uma lei própria que pró́be a pixação ${ }^{11}$ - portanto, anterior à lei federal, de $1998^{12}$. De lá para cá, o que muda, principalmente, são as formas com que se tenta fazer com que a lei seja conhecida, respeitada e cumprida, seja por meio de novas leis que alteram textos anteriores ${ }^{13}$, pela criação de órgãos específicos ao combate da prática, ou pela associação entre instituições e poderes, a fim de fechar o cerco e fazer cumprir as determinações. Além disso, busca-se a criação de medidas que envolvam e deem um retorno à comunidade, transformando as determinações da lei em enunciados de promoção da limpeza e beleza da cidade, tratadas como geradoras do bem-estar e da segurança da população.

Em 2010, por exemplo, foi publicada a "Política Municipal Antipichação ${ }^{14 "}$ e criado, pela Prefeitura de Belo Horizonte, o Movimento Respeito por BH (MRPBH) com o objetivo de "garantir o ordenamento e a correta utilização do espaço urbano, através do cumprimento e efetiva aplicação da legislação vigente”. São três as frentes de ação do movimento: 1) "Repressão qualificada", que prevê a utilização de redes de videomonitoramento a fim de inibir a ação dos pixadores; a manutenção de um catálogo, contendo as marcas e seus respectivos autores; e a identificação da autoria de pixações, seguida de busca e apreensão, realizada a partir de um monitoramento de meios eletrônicos; 2) "Sensibilização", que tem como objetivo traçar o perfil do pixador para que seja possível redirecionar suas motivações a outras formas de atuação na cidade; e 3) Ações de "despiche" para limpeza da paisagem urbana. Para desempenhar tais ações, o MRPBH trabalha em parceria com diversos órgãos, como as polícias Militar e Civil, a Guarda Municipal de Belo Horizonte, o Ministério Público de Minas Gerais, o Poder Judiciário, a Secretaria Municipal de Educação, a Empresa Municipal de Turismo - Belotur, a Superintendência de Limpeza Urbana - SLU, o Projeto Guernica ${ }^{15}$, entre outros.

11 Lei Municipal no 5998. Disponível em: <https://www.leismunicipais.com.br/a/mg/b/belo-horizonte/leiordinaria/1991/599/5998/lei-ordinaria-n-5998-1991-proibe-a-pichacao-de-muros-urbanos-em-belo-horizonte-e-preve-multapor-seu-descumprimento-1991-11-14.html>. Acesso em 11/10/2015.

12 Lei Federal no 9.605. Disponível em: <http://www.planalto.gov.br/ccivil_03/LEIS/L9605.htm\#art65>. Acesso em $11 / 10 / 2015$.

13 Lei Municipal no 6387, que regula a venda de tintas em spray. Disponível em: <http://cm-belohorizonte.jusbrasil.com.br/legislacao/237889/lei-6387-93>. E Lei Municipal nº 6995, que substitui a de 1991. Disponível em: <http://cm-belo-horizonte.jusbrasil.com.br/legislacao/237779/lei-6995-95>. Acesso em 06/11/2015. Acessos em 11/10/2015.

${ }^{14}$ Lei no 10.059. Disponível em: <http://portal6.pbh.gov.br/dom/iniciaEdicao.do?method=DetalheArtigo\&pk=1049831>. Acesso em 11/10/2015.

15 O Projeto Guernica foi lançado em 2000, pelo então Prefeito de Belo Horizonte, Célio de Castro, e tinha como objetivo inibir a ação não-autorizada dos pixadores e grafiteiros na cidade encontrando alternativas para sua atuação no espaço urbano. Em seu projeto inicial, o Guernica previa uma ampliação do debate com os próprios autores das intervenções, junto a profissionais das mais diversas áreas, a fim de que as motivações pudessem ser explicitadas e que eles pudessem refletir sobre elas, em um trabalho sistemático e contínuo. Previa, ainda, a formação de parcerias com diversos órgãos públicos e privados, inclusive os clubes de futebol da cidade (a pixação belo-horizontina sempre teve estreita relação com as torcidas organizadas de futebol), e, ainda, a realização de oficinas de cultura, arte e história. Mais informações sobre o projeto original em: <http://www.ptpr.org.br/pt_pag/PAG\%202004/CULTURA/Projeto\%20Guernica\%20-\%20Belo\%20Horizonte.PDF>. Acesso em 11/10/2015.Informações atuais sobre o Projeto no site da PBH:

_vol.09, nº. 04, Rio de Janeiro, 2016.pp. 2007-2024 2011


Há, ainda, outros projetos que vêm sendo constantemente discutidos pelo poder público municipal, como a criação de uma delegacia especializada em assuntos de pixação, anunciada diversas vezes pelo Prefeito Márcio Lacerda, em $2010^{16}, 2013^{17}$, e $2015^{18}$.

A articulação entre órgãos públicos no combate à pixação já demonstrou seu poder de ação por, pelo menos, duas vezes, nas prisões dos grupos Piores de Belô, em 2010 ${ }^{19}$, e Pixadores de Elite, em 2015 ${ }^{20}$, por formação de quadrilha. No primeiro caso, os seis pixadores presos ficaram encarcerados por 117 dias. No mais recente, em uma operação denominada Argo Panoptes ${ }^{21}, 17$ pixadores foram detidos, sendo que sete foram presos e dez foram alvos de condução coercitiva, passando a ser monitorados por tornozeleiras eletrônicas.

O MPMG ainda enviou à Justiça uma ação civil que propõe que os acusados ressarçam R 10 milhões aos cofres públicos, a serem destinados ao Fundo de Defesa dos Direitos Difusos Lesados ${ }^{22}$.

No entanto, ao mesmo tempo em que o poder se organiza em torno do combate à pixação, enquadrando-a e aos seus autores pelo crime, pelo descaso com a cidade e a comunidade, e pela total ausência de contribuição para o seu desenvolvimento, os pixadores surgem com outros modos de narrar a si mesmos e às suas experiências. Através de seu aparecimento público e do ato de assumirem-se como pixadores, somando a esse diversos outros nomes (e lugares, funções, habilidades e capacidades), esses sujeitos parecem tentar abrir a possibilidade de novas formas de entender o pixo. E se há uma articulação entre as instituições de poder para fortalecer as operações de combate, eles também têm contatos e meios para que suas falas, narrativas e visões de mundo sejam fortalecidas e circulem em espaços mais amplos, onlinee off-line.

\footnotetext{
$<$ http://portalpbh.pbh.gov.br/pbh/ecp/contents.do?evento=conteudo\&idConteudo=64026\&chPlc=64026\&\&pIdPlc=\&app=s alanoticias $>$. Acesso em 11/10/2015.

${ }^{16}$ Disponível em: <http://www.itatiaia.com.br/noticia/belo-horizonte-vai-ganhar-delegacia-especializada-no-combate-apichacao $>$. Acesso em 11/10/2015.

${ }^{17}$ Disponível em: <http://gl.globo.com/minas-gerais/noticia/2013/05/alem-de-sujarem-imoveis-pichadores-desafiam-policiaem-belo-horizonte.html >. Acesso em 11/10/2015.

${ }^{18}$ Disponível em: <http://www.alterosa.com.br/app/belo-horizonte/noticia/jornalismo/ja---2ed/2015/03/17/noticia-ja2edicao,131635/belo-horizonte-deve-ganhar-delegacia-especializada-para-pichadores.shtml >. Acesso em 11/10/2015.

${ }^{19}$ LAGÔA, Tatiana; LORENTZ, Jefferson. Pichadores são denunciados por formação de quadrilha. O Tempo (online), Belo Horizonte, 24 de agosto de 2010. Cidades. Disponível em: hhttp://www.otempo.com.br/cidades/pichadores-s\%C3\%A3odenunciados-por-forma\%C3\%A7\%C3\%A3o-de-quadrilha-1.231734>. Acesso em 12/10/2015.

${ }^{20}$ VIEGAS, Fernanda; CAZETTA, Jhonny. PM realiza operação para combater 'pichadores de elite' da RMBH. O Tempo (online), Belo Horizonte, 27 de maio de 2015. Cidades. Disponível em: <http://www.otempo.com.br/cidades/pm-realizaopera\%C3\%A7\%C3\%A3o-para-combater-pichadores-de-elite-da-rmbh-1.1045786>. Acesso em 12/10/2015.

${ }^{21}$ Argo Panoptes, na mitologia grega, era um gigante com cem olhos que, ao dormir, ainda mantinha 50 deles abertos. Disponível em: <https://pt.wikipedia.org/wiki/Argos_Panoptes>. Acesso em 26/06/2015.

${ }^{22}$ MATTOS, Litza. MPMG pede R\$10 mi de 'Pixadores de Elite.' O Tempo (online), Belo Horizonte, 14 de junho de 2015. Cidades. Disponível em: <http://www.otempo.com.br/mpmg-pede-r-10-mi-de-pixadores-de-elite-1.1054817>. Último acesso em 12/10/2015.
} 
Em Belo Horizonte, para além de seus grupos e points ${ }^{23}$, alguns pixadores têm aparecido em espaços e para pessoas que se vêem confrontadas com o universo da pixação de um modo que, possivelmente, nunca haviam sido antes. No primeiro semestre de 2014, dois eventos foram promovidos na cidade para o debate sobre o tema ${ }^{24}$ - O que é pixo?e Pixo é direito - e tiveram como objetivo a discussão pública sobre a pixação, contando com a participação de pesquisadores, advogados e representantes do poder público. Em ambos esses eventos de 2014, houve a presença significativa de pixadores, e aqueles que se apresentavam como tais sempre adicionavam àquela identidade outras tantas: "Meu nome é X, eu sou pixadora, pixo XX, sou mãe, faço faculdade e trabalho"; "meu nome é Z, sou pixador há 15 anos, e o pixo me afastou do crime na minha comunidade". Eles pediram a palavra, dividiram experiências e comentaram as atuais políticas e ações contra a pixação e seus praticantes. Eles ainda questionaram dados informados, os confrontaram com suas próprias experiências, reivindicaram mudanças no tratamento dado ao pixador quando ele é abordado pela polícia, pediram respeito, questionaram a necessidade de se apagar as marcas deixadas na cidade.

A particularidade desse ato de aparecer e assumir um ato e uma identidade publicamente reside no fato de que a pixação é um crime previsto pelas legislações federal e municipal, como pode ser visto na tabela abaixo.

\begin{tabular}{|c|c|c|c|}
\hline \multicolumn{4}{|c|}{ LEIS QUE DISPÕEM SOBRE O COMBATE À PIXAÇÃO (BRASIL E BELO HORIZONTE) } \\
\hline ÂMBITO & $\mathrm{LEI} / \mathrm{ANO}$ & PRINCIPAIS DISPOSIÇÕES & PENA PREVISTA \\
\hline Municipal & $\begin{array}{c}\text { Lei } \\
5998 / 1991^{25}\end{array}$ & $\begin{array}{l}\text { - Proíbe a pixação de muros urbanos, salvo sob } \\
\text { autorização do proprietário do imóvel. }\end{array}$ & $\begin{array}{l}\text { (Para o pixador) } \\
\text { Advertência e multa }\end{array}$ \\
\hline Municipal & $\begin{array}{c}\text { Lei } \\
6387 / 1993^{26}\end{array}$ & $\begin{array}{l}\text { - Regula a venda de tintas em spray apenas mediante } \\
\text { cadastro da identidade e endereço do comprador, } \\
\text { mantido em relatório. }\end{array}$ & $\begin{array}{l}\text { (Para o comerciante) } \\
\text { Multa e cassação do } \\
\text { Alvará de Localização e } \\
\text { Funcionamento }\end{array}$ \\
\hline Municipal & $\begin{array}{c}\text { Lei } \\
6995 / 1995^{27}\end{array}$ & $\begin{array}{c}\text { - Revoga a Lei } 5998 \text { e reforça a Lei 6387; } \\
\text { - Mantém a proibição à pixação, salvo sob } \\
\text { autorização do proprietário do imóvel. } \\
\text { - Caracteriza a pixação como “o ato de inserir } \\
\text { desenhos obscenos ou escritas ininteligíveis nos bens } \\
\text { móveis ou imóveis [...], sem autorização do } \\
\text { proprietário, com o objetivo de sujar, destruir ou }\end{array}$ & $\begin{array}{c}\text { (Para o pixador) } \\
\text { Advertência e multa }\end{array}$ \\
\hline
\end{tabular}

\footnotetext{
${ }^{23} \mathrm{O}$ point é o local de encontro e sociabilidade entre os pixadores. É onde eles se encontram para trocar experiências, assinaturas e materiais de coleção, além de marcar rolês (sair para pixar), festas, etc. (FRANCO, 2009; LASSALA, 2010; PEREIRA, 2005).

${ }^{24} \mathrm{O}$ debate "O que é pixo?", realizado na programação do Café Controverso, promovido pelo Espaço UFMG do Conhecimento, em 12 de abril de 2014. O evento "Pixo é Direito: diálogo aberto entre pixação e direito", realizado em 16 de maio de 2014, na Faculdade de Direito da Universidade Federal de Minas Gerais, pelo projeto Cidade e Alteridade.

${ }_{25}$ Texto completo da Lei no 5998 disponível em: <https://www.leismunicipais.com.br/a/mg/b/belo-horizonte/leiordinaria/1991/599/5998/lei-ordinaria-n-5998-1991-proibe-a-pichacao-de-muros-urbanos-em-belo-horizonte-e-preve-multapor-seu-descumprimento-1991-11-14.html>. Acesso em 11/10/2015.

${ }^{26}$ Texto completo da Lei no 6387 disponível em: <http://cm-belo-horizonte.jusbrasil.com.br/legislacao/237889/lei-6387-93> Acesso em 11/10/2015.

${ }^{27}$ Texto completo da Lei 6995 disponível em: <http://cm-belo-horizonte.jusbrasil.com.br/legislacao/237779/lei-6995-95>. Acesso em 06/11/2015.
} 


\begin{tabular}{|c|c|c|c|}
\hline & & ofender a moral e os bons costumes"; & \\
\hline Federal & $\begin{array}{c}\text { Lei } \\
9.605 / 1998^{28}\end{array}$ & $\begin{array}{l}\text { - Lei de Crimes Ambientais } \\
\text { - Caracteriza como crime pixação e grafite }\end{array}$ & $\begin{array}{c}\text { (Para o pixador e o } \\
\text { grafiteiro) } \\
\text { Multa e detenção de três } \\
\text { meses a um ano. }\end{array}$ \\
\hline Municipal & $\begin{array}{c}\text { Lei } \\
10.059 / 2010^{29}\end{array}$ & $\begin{array}{c}\text { - Cria a "Política Municipal Antipichação"; } \\
\text { - Propõe a divulgação e a intensificação da } \\
\text { fiscalização do cumprimento das leis já existentes; } \\
\text { - Propõe promover o envolvimento dos cidadãos e } \\
\text { do setor privado na recuperação dos espaços pixados; } \\
\text { - Visa a "inserir socialmente" os pixadores, } \\
\text { estimulando outras formas de relação com o espaço } \\
\text { urbano municipal. }\end{array}$ & Não dispõe sobre penas. \\
\hline Federal & $\begin{array}{c}\text { Lei } \\
12.408 / 2011\end{array}$ & $\begin{array}{c}\text { - Altera a Lei } 9.605 \\
\text { - Descriminaliza o grafite (feito com autorização), } \\
\text { mantendo a pixação como crime ambiental. } \\
\text { - Regula a venda de tintas em sprayapenas a maiores } \\
\text { de } 18 \text { anos, mediante apresentação de RGe } \\
\text { identificação na nota fiscal. }\end{array}$ & $\begin{array}{c}\text { (Para o pixador) } \\
\text { Multa e detenção de três } \\
\text { meses a um ano. }\end{array}$ \\
\hline Municipal & $\begin{array}{c}\text { Portaria } \\
088 / 2015^{30}\end{array}$ & $\begin{array}{c}\text { - Segue recomendação do MPMG, solicitando à } \\
\text { PBH a adoção de medidas mais eficazes para o } \\
\text { combate ao pixo }{ }^{31} \text {; } \\
\text { - Prevêe intensificação da fiscalização das leis de } \\
\text { combate à pixação; } \\
\text { - Prevê medidas contra proprietários ou responsáveis } \\
\text { por imóveis que não mantenham suas fachadas } \\
\text { limpas das pixaçães; } \\
\text { - Define os órgãos municipais responsáveis por cada } \\
\text { uma das medidas que compõem a “Política } \\
\text { Municipal Antipichação”; } \\
\text { - Oficializa a cooperação entre a Secretaria Municipal } \\
\text { de Serviços Urbanos e órgãos a ela vinculados com o } \\
\text { Ministério Público Estadual, a Secretaria de Estado } \\
\text { de Defesa Social, e as polícias Civil e Militar de Minas } \\
\text { Gerais. }\end{array}$ & $\begin{array}{l}\text { (Para proprietários de } \\
\text { imóveis) } \\
\text { Auto de Notificação aos } \\
\text { que não limpem } \\
\text { pixações em suas } \\
\text { fachadas. }\end{array}$ \\
\hline
\end{tabular}

É interessante observar que, nesses eventos, a descriminalização do pixo não foi uma demanda apresentada, mas, de certo modo, o que se pede é justamente a atenção às leis que proíbem a prática. Um dos pontos mais instigantes, então, é que os pixadores assumem seu lugar como transgressores da lei, mas

\footnotetext{
${ }^{28}$ Texto completo da lei no 9.605 disponível em: <http://www.planalto.gov.br/ccivil_03/LEIS/L9605.htm\#art65>. Acesso em $11 / 10 / 2015$.

${ }^{29}$ Texto completo da Lei $\quad \mathrm{n}^{\mathrm{O}} \quad 10.059 \quad$ disponível em:

<http://portal6.pbh.gov.br/dom/iniciaEdicao.do?method=DetalheArtigo\&pk=1049831>. Acesso em 11/10/2015.

${ }^{30}$ Texto completo da Portaria 088/2015 disponível em:

<http://portal6.pbh.gov.br/dom/iniciaEdicao.do?method=DetalheArtigo\&pk=1151064>. Acesso em 11/10/2015.

${ }^{31}$ Disponível em: <http://www.otempo.com.br/cidades/mp-expede-recomenda\%C3\%A7\%C3\%A3o-para-pbh-adotar-medidasde-combate-\%C3\%A0-picha\%C3\%A7\%C3\%A3o-1.1130939>. Acesso em 11/10/2015.
} 
demonstram saber qual lei infringem e qual não thes diz respeito. É desse lugar que esperam ser ouvidos e terem suas falas consideradas, e isso já configura um conflito importante. Para um advogado presente no debate Pixo é direito, o que os pixadores demandam é um direito à transgressão: que eles sejam punidos como é previsto pela lei, com os direitos individuais e humanos respeitados.

Um evento de caráter bem diverso, mas que também dá a ver esses modos diferentes de inscrição da pixação e dos pixadores na comunidade, foi o $1^{\circ}$ Real Grapixação Socia $\beta^{2}$, que aconteceu no dia 31 de maio de 2015, na Vila Califórnia, região Noroeste de Belo Horizonte. O evento, concebido por um dos pixadores presos no caso dos Piores de Belô e promovido por sua loja (onde comercializa materiais para a produção de grafite, roupas e acessórios), teve como objetivo promover um domingo de entretenimento e solidariedade às crianças daquela comunidade, com a presença e o envolvimento de diversos pixadores, grafiteiros e outros parceiros na arrecadação e distribuição de roupas, brinquedos e livros. Houve, ainda, o oferecimento de uma oficina de grafite, que tinha como objetivo despertar o "interesse da comunidade local" pela expressão; e a produção coletiva de um mural de grapixos - chamado de "sopa de letras" - no muro da creche que recebeu o evento. A intenção, segundo texto que consta no evento criado no Facebook, seria proporcionar aos moradores daquela comunidade, especialmente às crianças, uma forma de inserção social pela arte. Fotos, vídeos e depoimentos produzidos ou coletados durante o evento foram publicados em páginas da rede social que defendem e divulgam a pixação como expressão artística e forma de saber, como Pixo Livre ${ }^{33}$ e Cultura de Rua ${ }^{34}$.

Esses três eventos são apenas exemplos de como a noção do que é ser pixador em Belo Horizonte não está encerrada nas representações definidas pelo poder público e pelas leis, mas é construída, também e de modo diferente, pelos próprios pixadores, em interação com outros sujeitos que se colocam ao seu lado. $\mathrm{O}$ mais interessante, nesse contexto, é que não se trata de uma luta centrada em tornar a prática da pixação legal, mas em questionar os modos de repressão, como se os pixadores quisessem fazer parte das discussões que determinam como eles mesmos serão punidos.

Uma pixadora presente no debate $O$ que é pixo $?^{35}$, por exemplo, declarou que quando um pixador é pego em flagrante, o problema não está em ir para a delegacia; eles têm consciência de que aquilo que fazem é proibido por lei e passível de punição. O problema, para ela, é tudo o que ocorre entre a abordagem do policial e a chegada à delegacia, isso quando eles são encaminhados até lá, já que, muitas vezes, os policiais se restringem a uma punição física e moral imediata, na rua (como cobrir o pixador com a tinta que ele portava). Nesse mesmo sentido, "Goma", em um vídeo produzido pela frente Cultura de Rua do projeto Cidade e Alteridade, da Faculdade de Direito da UFMG, dá um depoimento sobre o evento de sua prisão no caso dos Piores de Belô:

\footnotetext{
${ }^{32}$ Disponível em: <https://www.facebook.com/events/385985938256041/>. Acesso em 26/06/2015.

${ }^{33}$ Disponível em: <https://www.facebook.com/pixolivre>. Acesso em 27/06/2015.

${ }^{34}$ Disponível em: <https://www.facebook.com/culturaderuaufmg >. Acesso em 27/06/2015.
} 
$\mathrm{Na}$ época, assim, eu fiquei preso e eu fazia isso tudo: faculdade, serviço de carteira assinada, residência própria, entendeu? Eu tinha acabado de ser pai. Tipo, pra mim foi uma injustiça enorme. Eu com 28 anos, na época, nunca tinha sido preso na minha vida. Na época de adolescente aí até a gente aprontava direto, mas nunca fui preso, só pixação mesmo, vai pra delegacia, vai embora. E paga, né? Serviço comunitário, do jeito que tem que ser mesmo, agora forjar ${ }^{36}$ foi foda. (DEPOIMENTO) ${ }^{37}$

Para o advogado Felipe Bernardo Furtado Soares, responsável pela defesa de uma jovem detida na operação que prendeu os Pixadores de Elite, "enquadrar pixação como formação de quadrilha é criminalizar essa cultura e também criminalizar uma forma de amizade, uma forma de socialização que os meninos têm. Porque a finalidade da associação dele não é a prática do crime, mas sim é [a de] criar amizades”38.

Outro exemplo das articulações dos pixadores é o grupo Real da Rua, formado em 2012 por uma parceria entre o coletivo Família de Rua ${ }^{39}$ e a ONG Pacto ${ }^{40}$ com o objetivo de ser um conselho formado pelas pessoas que ocupam e fazem uso do Viaduto Santa Tereza, entre adeptos do movimento hip-hop, do skate, do pixo, moradores de rua, estudantes, ambulantes, entre outros. A ideia é a de participar ativamente dos debates e processos decisórios que envolvam o Viaduto e seu entorno, uma ideia traduzida na frase "Nenhuma palavra de nós sem nós ${ }^{41}$ ". O grupo se reúne periodicamente embaixo do Viaduto para discutir os modos de ocupação do espaço, as ações do poder público, eventos específicos que envolvam o local e/ou os públicos de interesse, além de articular ações estratégicas para fomentar o debate público sobre as questões que cercam as diversas formas de expressão cultural urbana existentes na cidade. Por vezes, são convidados representantes de órgãos públicos para estabelecer um diálogo entre a margem e o centro desse debate.

Certeau (1998) aponta que as estratégias são definidas pela lei do lugar, dizendo quem pode fazer o que, em que momento e de que forma. Já as táticas não obedecem a essas definições, criando novas formas de habitar o mundo, jogando com as imposições estratégicas, transformando espaços a partir do questionamento de uma ordem vigente e da abertura de espaços para expressão e visibilidade por aqueles que não eram contados como partes de um comum. Em pesquisas anteriores (OLIVEIRA 2008; 2015; OLIVEIRA, FONSECA e MARQUES, 2011), as intervenções gráficas urbanas vinham sendo entendidas como táticas desenvolvidas pelos sujeitos

\footnotetext{
${ }^{35}$ Vídeo com a íntegra do debate disponível em: <https://www.youtube.com/watch?v=vT16nu06214>. Acesso em 26/05/2015.

${ }^{36}$ De acordo com Goma, a polícia forjou o esquema da associação para o pixo a fim de que fosse possível enquadrar os pixadores no código de formação de quadrilha. Segundo ele, ele nunca sequer havia pixado com alguns dos pixadores com quem foi preso sob essa acusação.

${ }^{37}$ Depoimento Goma - O Caso dos Piores. Cultura de Rua UFMG. Belo Horizonte, 5 de março de 2015. Vídeo. Disponível em: $<$ https://www.youtube.com/watch?v=kDJOzXidxZc>. Acesso em 27/06/2015.

${ }^{38}$ DECLERCQ Marie. Belo Horizonte declarou guerra ao pixo. Vice Brasil, 23 de junho de 2015. Disponível em: <http://www.vice.com/pt_br/read/belo-horizonte-declarou-guerra-ao-pixo>. Acesso em 26/06/2015.

${ }^{39} \mathrm{O}$ coletivo Família de Rua é responsável pela realização do Duelo de MC's, evento de hip-hop que ocorre desde 2007 no Viaduto Santa Tereza, em Belo Horizonte, e que enfrenta, frequentemente, a resistência da PBH. Página do coletivo no Facebook disponível em: <https://www.facebook.com/familiadrua>. Acesso em 12/10/2015.

${ }^{40}$ A ONG Pacto Desenvolvimento Social e Pesquisa foi fundada em junho de 2006 e "se interessa pela convivência nas cidades, pelos conflitos e soluções inventados diante dos impasses daí decorrentes”. Disponível em: <http://www.pactodsp.org/>. Acesso em 12/10/2015.
} 
ordinários para se expressarem na cidade, a partir e apesar das estruturas e condições nela oferecidas. Contudo, no panorama que se observa agora, se faz necessário ampliar o entendimento sobre táticas e estratégias, suspendendo possíveis relações diretas com ações marginais e oficiais, respectivamente, e buscando entender como elas se atravessam nos movimentos empreendidos por cada lado. Quando os membros do grupo Real da Rua se organizam a fim de pautar o debate público oficial sobre a cultura urbana, inclusive convidando representantes de órgãos do poder público para o diálogo, isso se configura como uma estratégia, muito mais que como uma tática, pois propõe afetar as determinações oficiais, e não apenas agir furtivamente dentro delas. Há certo conhecimento das ações empreendidas pela gestão municipal, das leis, das operações, e ele é usado como base para a discussão, junto com as experiências dos próprios sujeitos que vivenciam, circulam e se expressam na cidade diariamente. De todo modo, ainda que o objetivo seja o de buscar as interações, atravessamentos e tensões entre poder público e pixação, é importante olhar com atenção para os modos como cada um desses âmbitos se articula.

Em movimentos como esses, os pixadores aparecem de modos bastante distintos daqueles em que são apresentados pelo poder público, e o fazem através de suas próprias formas de narrar suas vidas, suas experiências com o pixo e a cidade, e também através do diálogo com outros sujeitos - pesquisadores, advogados, etc. - que afirmam se colocar não à sua frente, mas ao seu lado. Através de seu aparecimento público e do ato de assumiremse como pixadores, somando a esse diversos outros nomes (e lugares, funções, habilidades e capacidades), esses sujeitos parecem tentar abrir a possibilidade de novas formas de entender o pixo e as cenas conflituais que o configuram como prática e gesto político.

\section{CENAS DE ENUNICAÇÃO E SUJEITOS POLÍTICOS}

Segundo Rancière (1996; 2009), a autonomia dos atores sociais, a validade de seus argumentos e os seus horizontes de ação não são dados a priori, mas derivam de uma produção discursiva dos sujeitos que, a partir da verificação de uma igualdade pressuposta, conseguem perturbar a ordem vigente e fazer com que sua fala passe a ser contada como palavra e não mais como ruído.

Para o autor, a política estaria vinculada a uma potência poética, comunicacional e produtiva de criação de "cenas de dissenso", que abrem espaço para que aqueles que não eram contados passem a ser por meio do ato de tomar a palavra e enunciá-la/performá-la diante dos outros, em uma ação de verificação da igualdade que questiona, em ato, a ordem que determina quem está apto a fazer parte do comum, a aparecer nele, a ter sua fala ouvida como discurso. A cena de dissenso é criada para reconfigurar tal ordem e trazer novos indivíduos e elementos sensíveis ao comum. Tal reconfiguração, contudo, não se cristaliza, mas funciona no litígio entre a ordem dada e a cena em construção.

\footnotetext{
${ }^{41}$ Disponível em: <https://www.facebook.com/RealdaRua/info>. Acesso em 31/08/2014.
} 
É na "cena dissensual" que os atores criam atos enunciativos por meio dos quais inauguram um tempo e um espaço capazes de permitir novos recortes e territorializações do espaço material, legal e simbólico. Tomar a palavra ou tomar posse dos recursos necessários à expressão de si é importante nesse processo, pois a centralidade da subjetivação política, de acordo com Rancière, está justamente nas formas novas de circulação das palavras, de exposição do visível e de produção de afetos que determinam capacidades novas, as quais alimentam práticas de emancipação.

A subjetivação, em Rancière, nomeia tanto o processo de se tornar sujeito quanto o processo político de nomear constrangimentos de poder e injustiças: ela torna visível o hiato entre a identidade de alguém dentro da ordem consensual dada (na distribuição de papéis, lugares e status) e uma certa demanda de subjetividade por meio da ação da política. Sob esse aspecto, Rancière ressalta que, por subjetivação entende-se "a produção, por uma série de atos, de uma instância e de uma capacidade de enunciação que não eram identificáveis em um campo de experiência dado, cuja identificação está ligada à reconfiguração do campo da experiência" (1996, p.59). A subjetivação política não é o "reconhecimento de" ou o gesto de "assumir uma identidade", mas o desligamento com essa identidade, a produção de um hiato e uma disjunção entre a identidade da ordem vigente e uma nova subjetividade política. A disjunção e a ruptura são promovidas pelo sujeito político no plano da experiência sensível, sendo que, para Rancière (1995), o sensível se refere a lugares e modos de performance e de exposição, formas de circulação e de reprodução dos enunciados -, mas também aos modos de percepção e dos regimes de emoção, às categorias que os identificam, esquemas de pensamento que os classificam e os interpretam.

Quando observamos o cenário aqui apresentado sobre o sistema criado pelo poder público de Belo Horizonte para combater a pixação na cidade, pode-se observar que na distribuição dos corpos em sociedade, na divisão dos espaços e na administração dos tempos, desenvolvidos a fim de gerir e manter certos usos, ocupações e fluxos dentro da cidade, deixar visível aquilo que destoa do planejamento revela uma fratura que não se deseja expor: certa dificuldade para fazer cumprir aquilo que a lei determina, o que significa não apenas um erro no sistema jurídico, mas uma falha na própria tentativa de reduzir a potência e a pluralidade das ações dos sujeitos a normas racionais que visam ao seu controle.

Os pixadores não desejam subverter ou tomar o poder, a não ser aquele sobre seus corpos e ações. O que incomoda é, justamente, o modo como eles escapam, furtivos, em suas práticas noturnas e invisíveis, a não ser pelo rastro deixado nas marcas; é a ilegibilidade dessa mesma marca, que não comunica a todos, não decora (dentro de determinados padrões de beleza da cidade), e não apresenta, assim, vantagens e ganhos palpáveis à comunidade. A não compreensão é entendida como ameaça por quem não compartilha do código, ao mesmo tempo visível e oculto. Não sabendo como lidar, impõe-se a proibição; a restrição a uns pela liberdade e bem-estar dos outros. 
Nesse movimento, como é apontado por Rancière (1996), a justiça se transforma em um jogo de perdas, ganhos e ressarcimento de danos, ao invés de trabalhar pelo seu tratamento. ${ }^{42}$ Mesmo quando diz se propor ao entendimento das motivações que levam à pixação, como aparece em alguns momentos no texto sobre o Movimento Respeito por BH, essa proposta é feita de cima para baixo, e não parte de um diálogo, como expõe uma pixadora presente no debate $O$ que é pixo?, que disse que o poder diz querer estabelecer uma conversa que só é possível quando os termos são impostos por ele.

Dessa forma, quando os pixadores, por meio de suas próprias falas e ações, apresentam-se também como universitários, trabalhadores, pais/mães, entre outros nomes, eles se desidentificam com certa figura criada pelo poder público como o "pichador" (com "ch", denominado pela ordem), suspendem sua relação direta com o crime, e criam a sua própria, com sua própria linguagem: pixador, um nome ao qual parecem estar ligadas incontáveis possibilidades, trazidas à cena pelo ato de aparecer e tomar a palavra.

Para Rancière (1995), ser contado enquanto parte de uma comunidade está diretamente ligado à capacidade da palavra e da linguagem, em oposição ao ruído que apenas emite prazer ou dor, pois "entre a linguagem daqueles que têm um nome e o mugido dos seres sem nome, não há situação de troca linguística que possa ser constituída, não há regras ou código para a discussão" (RANCIÈRE, 1996, p.37). E aqui é importante assinalar, como destaca Chambers (2013), como a dimensão do dizível não pode ser desvinculada da dimensão do visível no pensamento político de Rancière. Fazer-se visto e ouvido onde antes não se era, por meio de um trabalho próprio com a linguagem, é uma forma de inscrever-se dissensualmente em uma cena, expor o dano, e apontar para outras possibilidades de partilha do sensível.

Hannah Arendt $(2007 ; 2000)$ também argumenta sobre a importância da "aparência” para a política. Para a autora, o espaço da aparência existe quando (e somente enquanto) os indivíduos se reúnem discursiva e ativamente (também para ela duas dimensões inseparáveis), algo que precede qualquer organização formal da esfera pública. Para Arendt, ainda que um indivíduo tenha, isoladamente, grande força, é nesse espaço de aparência, na união com outros indivíduos, que ele pode, junto com os demais, possuir poder. Assim, o ser em comum não se reduz a um "modo de ser", mas aponta para o aparecer em comum dos seres, sem desconsiderar que os modos de aparecer são sempre plurais (como são também as existências). E, conforme observado por Tassin (2012), esse aparecimento de um ator na cena pública enquanto um ser singular de ação e discurso marca,

\footnotetext{
${ }^{42}$ É importante destacar que o dano não pode ser confundido com uma injúria cometida contra um sujeito específico, ou seja, algo que pode ser reparado ou "consertado" pela aplicação de uma lei ou sanção. Não se repara o dano, no sentido de fazer com que ele desapareça, mas se pode tratá-lo a partir do momento em que se instaura o dissenso entre uma ordem policial (de saturação da equivalência entre corpos e ocupações) e a irrupção da política. Interessa a Rancière, portanto, uma "cena na qual se colocam em jogo a igualdade ou a desigualdade dos parceiros de conflito enquanto seres falantes” (1995, p.81), uma cena de demonstração para o tratamento do dano.
} 
ainda, a emergência do mundo comum e do espaço público no qual o sujeito político cria possibilidades de afastamento das atribuições a ele conferidas hierarquicamente.

A formação de um mundo comum está intimamente ligada à construção pragmática do espaço público, compreendido por Tassin como "jogo de separações vinculantes e de vínculos separadores" (1992, p.33). O espaço público, enquanto mundo comum, abrange, em primeiro lugar, uma pluralidade de comunidades que só se transformam em "comunidade de uma pluralidade", porque o espaço público é intervalar, isto é, ele conecta sujeitos e universos particulares para dar origem a um "être-en-commun", e a um "vivre ensemble" marcado por interrupçoes, fraturas e intervalos de subjetivação. Esta última, implica a descoberta de uma capacidade de enunciação que não podia ser identificada em um campo previamente existente da experiência. A produção de um novo campo de experiência requer, portanto, uma concepção de comunidade que ofereça brechas para o questionamento das "identidades e dos lugares definidos em um espaço determinado em um mundo já dado; identidades e lugares definidos à exemplo de outros espaços; e identidades e lugares que não têm espaço" (RANCIÈRE, 1995, p.186). Viver juntos e em meio a fraturas torna-se mais desafiante que "ser em comum", uma vez que viver com o outro requer sua consideração, a apreensão sensível de seu mundo e de suas marcas sem necessariamente incorporá-las ao próprio universo ou aprisioná-las no discurso.

E talvez esteja aí uma razão para o apontamento feito por Foucault (1999) sobre o temor causado pela potência do discurso, "dessa massa de coisas ditas, do surgir de todos esses enunciados, de tudo o que possa haver aí de violento, de descontínuo, de combativo, de desordem, também, e de perigoso, desse grande zumbido incessante e desordenado" (FOUCAULT, 1999, p.50). Tal temor leva a inúmeras tentativas de organizar, controlar, dominar o discurso, a fim de determinar quem pode ou não falar, sobre o quê e em que momentos. É preciso, então, de acordo com o autor, olhar para os discursos buscando o que neles revela esses procedimentos de exclusão e rarefação. Para Rancière (1995; 2009), é justamente a partir do questionamento sobre uma ordem policial que determina quem pode falar o quê sobre o quê em que momentos, sobre qual linguagem é legítima, etc., que a política ocorre, abrindo espaços para a reconfiguração de uma dada ordem do sensível através do desentendimento e do dissenso, os quais sedimentam os processos de constituição de comunidades políticas.

A comunidade política de partilha, segundo Rancière, surge de uma definição da igualdade que possibilita a afirmação de cada indivíduo como alguém que compartilha um mundo comum e, ao mesmo tempo, preserva os intervalos entre uma multitude de experiências individuais. Tal definição pode dar a ver um tipo de comunidade em que todos deveriam tratar seus parceiros de interação como iguais, com base no fato de que todos são potenciais interlocutores, capazes de falar e dignos de serem ouvidos e considerados. Mas essa igualdade não é dada a priori. Ela só é alcançada por meio de "testes" concretos de verificação que desafiem o entendimento (o já dado) de que existem princípios de igualdade que asseguram, de antemão, o acesso de todos vol.09, nº. 04, Rio de Janeiro, 2016. pp. 2007-2024 2020 
os indivíduos à linguagem, à visibilidade e à interlocução. Por isso, para Rancière, a comunidade é inconsistente e intervalar: ela se mantém suspensa devido ao ato constante de sua verificação por homens que trabalham pela criação contínua da igualdade (2004, p.162). Para Rancière, formas de agir e de ser do sujeito que tendem mais ao desentendimento permitem instaurar uma comunidade política de partilha na qual a igualdade é o exercício constante de regular a proximidade e a distância entre seus membros. Seria preciso, então "aprender a recriar a cada instante o próximo e o distante que definem os intervalos da comunidade" (2004, p.199).

O vínculo e os modos de ação dos membros que integram uma comunidade dessa natureza privilegiam não uma reafirmação das diferenças entre grupos, mas uma reconfiguração da distribuição de ordens do visível, do audível e do comunicável, deslocando os limites e questionado uma ordem sensível excludente.

Formas de comunidade política não têm como objetivo fazer coincidir semelhantes e desemelhantes, mas revelar que a partilha de um mundo comum é feita, ao mesmo tempo, da tentativa de estabelecer ligações entre universos fraturados e da constante resistência à tentativa integradora (às vezes até opressora) desses vínculos.

No caso aqui apresentado, poder público e articulações entre pixadores não devem ser observados como dois âmbitos separados e opostos, mas como atores distintos em uma cena e uma comunidade mais ampla de discussão, que ainda que se configure de forma conflituosa e dissensual, apresenta atravessamentos, entrecruzamentos, negociações e mútua afetação. Isso requer compreender o encadeamento das ações, propostas, reações e resistências, dando a ver como cada sujeito e coletivo se inscrevem na cena, como se apresentam, que argumentos evocam, que demandas enunciam, que performances desempenham a fim de alterar uma ordem sensível de partilha do comum e da cidade.

\section{CONSIDERAÇÕES FINAIS}

Neste trabalho procuramos construir um olhar analítico e crítico mais amplo para a pixação enquanto forma de expressão e representação que guarda uma potência de sentido e ação para além de sua materialidade (e também nela). Ou seja, um olhar que busca compreendê-la como produto de um processo que pode envolver o engajamento de sujeitos conscientes de suas ações, que se articulam em redes de sociabilidade complexas, e que produzem seus próprios sentidos sobre a cidade e seus modos de relação com ela, com os quais negociam com as determinações do poder público. Isso não significa dizer que todo pixador está conscientemente engajado em uma luta política por reconhecimento ou por influenciar processos administrativos da cidade. Significa, sim, que há, na própria apropriação dos espaços e na criação de novas formas de aparecimento, enunciação e relacionamento, uma potência política, que pode se realizar na transformação das formas de participação na vida social, nos modos de ver e ser visto, nas possibilidades de falar e ser ouvido, na reconfiguração de um mundo 
comum. Ou não se realizar, uma vez que as ações dos pixadores e dos sujeitos com os quais se articulam não resultam, necessariamente, em uma maior participação, tomada de palavra ou reconhecimento como parte de um comum.

É importante lembrar que o "comum" é, ao mesmo tempo, o que une e o que separa, o consenso e o dissenso, a rendição e a resistência. Ele pode ser descrito como a "dimensão intervalar na qual nos remetemos uns aos outros e a nós mesmos", configurando-se por meio da "instituição de intervalos que ligam sujeitos e realidades, sem englobá-los nem integrá-los" (TASSIN, 1992, p.33). O comum de uma comunidade é menos aquilo que é "próprio" de um grupo ou de uma cultura e mais o lugar de exposição e aparecimento dos intervalos e das brechas que permitem uma ação comum através da linguagem, de modo a promover não formas de "ser em comum” (que apagam ou incorporam diferenças, suprimindo singularidades), mas formas de "aparecer em comum". Eis aqui uma questão central: o "comum" de uma comunidade diz do "aparecer" dos sujeitos na esfera de visibilidade pública como interlocutores dignos de respeito e estima.

Em Belo Horizonte, o movimento de aparecer e se assumir pixador vem sendo movido, principalmente, pelo questionamento sobre o tratamento endereçado pelo poder público municipal aos pixadores. É possível identificar um movimento de afastamento dos nomes, lugares e funções destinados aos pixadores, o que Rancière (1996) denomina como "desidentificação", uma das bases do processo de subjetivação política. Como vem sendo possível observar pela participação em alguns eventos e espaços dedicados a debater o pixo na cidade, ele parece se dar, predominantemente, pela recusa da identidade de bandido, o que é feito com a assunção de múltiplos nomes juntos ao de pixador (como mãe/pai, trabalhador, universitário, etc.), e com a associação a outros sujeitos, que se colocam ao lado dos pixadores para debater sobre o pixo, os espaços urbanos, as ações do poder público, e sobre como tudo isso impacta em suas formas de existir e de serem vistos na cidade.

Assim, as ações e articulações de resistência empreendidas pelos pixadores, ao irromperem em meio à ordem vigente, no mínimo embaralham as visões e os sentidos criados ao redor do pixo e de seus autores. E, se há um momento de suspensão nessas determinações, há a possibilidade de inserir aí outros horizontes possíveis, em que os pixadores mostram sua capacidade de compreender a linguagem do poder, de interpretá-la a partir de suas experiências, de misturá-la à sua própria linguagem a fim de tensionar vida e norma. De todo modo, é preciso reconhecer que por mais que esses sujeitos - por meio de sua prática ou do ato de assumir publicamente seus papeis múltiplos e dificeis de classificar - consigam escapar cotidianamente por entre os dedos do poder e se inserir nos espaços onde não eram contados (de formas que não eram permitidas, muitas vezes, quando esse mesmo poder resolve reafirmar sua força), pode tornar-se muito difícil resistir a todo um complexo mecanismo posto em ação para inventar novas formas de criminalização do pixo. Aí, novas ações são demandadas: novos debates, a ampliação da rede de apoio, o esforço por fazer circular de forma mais ampla as narrativas do pixo feitas de dentro (ou do lado). 
A comunicação, enquanto processo relacional e prática reflexiva, é a chave que permite uma reconfiguração do "comum” e dos intervalos entre os sujeitos (dimensão estética), articulando, no espaço público, um questionamento constante dos pressupostos igualitários que definem o que é tido como político e quem é capaz de enunciá-lo, compreendê-lo e de discuti-lo.

\title{
PIXO AND DISSENSUAL SCENES IN BELO HORIZONTE: ANTAGONISMS BETWEEN THE LAW FORCE AND THE EMERGENCE OF PIXADORES AS POLITICAL SUBJECTS
}

\begin{abstract}
The aim of this article is to evidence how the government of Belo Horizonte has intensified the fight against pixação in the city at the same time that pixadores have appeared publicly with new ways of narrating the pixo and their experiences. In these two spheres, there are two completely different constructions of what means to "be a pixador" by setting a tense and dissensual scene of interaction. Rather than isolate or oppose these spheres, we search to understand how the pixadores can use the features of this scene to appear as political subjects.
\end{abstract}

Palavras-chave: pixadores; poder público; scenes of dissensus; political subjects.

\section{REFERENCIAS}

ARENDT, H. A condição humana. Rio de Janeiro: Forense, 2007.

A vida do espírito. Rio de Janeiro: Relume Dumará, 2000.

BAUDRILLARD, J. Kool Killer ou a insurreição pelos signos. Tradução: Fernando Mesquita. Revista Cine-Olho, no5/6. São Paulo: jun/jul/ago, 1979. Disponível em: <http://seraphimfotos.blogspot.com.br/2006/11/koolkiller-ou-inssurreio-pelos-signos.html>. Acesso em 30/03/2014.

CHAMBERS, S. The Lessons of Rancière. New York: Oxford University Press, 2013.

FOUCAULT, M. A ordem do discurso. Tradução de Laura Fraga de Almeida Sampaio. São Paulo: Edições Loyola, 1999.

FRANCO, S. M. Iconografias da metrópole: grafiteiros e pixadores representando o contemporâneo. Dissertação de mestrado. Área de Concentração: Projeto, Espaço e Cultura. São Paulo: FAU/USP, 2009.

GITAHY, C. O que é Graffiti. São Paulo: Brasiliense, 2012.

KNAUSS, P. “Grafite Urbano Contemporâneo”. In: TORRES, Sônia (org). Raízes e Rumos. Rio de Janeiro: 7 letras, 2001.p. 334-353.

LASSALA, G. Pichação não é Pixação: uma introdução à análise de expressões gráficas urbanas. São Paulo: vol.09, no. 04, Rio de Janeiro, 2016. pp. 2007-2024 2023 
Altamira Editorial, 2010.

OLIVEIRA, Ana Karina de Carvalho. Vozes marginais no espaço urbano: os stickers no Centro de Belo Horizonte. Monografia de conclusão de curso de Graduação. Área de concentração: Comunicação Social com Habilitação em Publicidade e Propaganda. Belo Horizonte: Faculdade Promove, 2008.

OLIVEIRA, A. K. C.; FONSECA, C. G; MARQUES, A. C. S. "Superfície da cidade: arte, cotidiano e política nas intervenções urbanas”. Revista Rumores, São Paulo, v.9, n.18, jul-dez, 2015. Disponível em: [http://www.revistas.usp.br/Rumores/article/view/99473/107017]. Acesso em 10 de abr. de 2016.

OLIVEIRA, A. K. C. "Agora é a vez do pixo": cenas de dissenso e subjetivação política nas relações entre pixação e arte. Dissertação de Mestrado. Área de concentração: Comunicação e Sociabilidade. Belo Horizonte: Universidade Federal de Minas Gerais, 2015.

PEREIRA, A. B. De rolê pela cidade: os pixadores em São Paulo. Dissertação de mestrado. Área de Concentração: Antropologia Social. São Paulo: USP, 2005.

RANCIÈRE, J. A partilha do sensível. Estética e política. Trad. Mônica Costa Netto. São Paulo: Editora 34, 2009. O desentendimento: Política e Filosofia. Trad. Ângela Leite Lopes. São Paulo: Ed. 34, 1996. La Mésentente-politique et philosophie. Paris: Galilée, 1995. Aux bords du politique. Paris: Gallimard, 2004.

TASSIN, E. Espace commun ou espace public? L'antagonisme de la communauté et de la publicité. Hermès, v.10, 1992, p.23-37.

"De la subjectivacion politica. Althusser/Rancière/Foucault/Arendt/Deleuze". Revista de Estudias Sociales v.43, Edicions Uniandes, agosto 2012, p. 36-49.

Trabalho enviado em 14 de abril de 2016.

Aceito em 20 de julho de 2016. 